\title{
EDUCAÇÃO DE JOVENS E ADULTOS TRABALHADORES DE QUALIDADE: REGIME DE COLABORAÇÃO E SISTEMA NACIONAL DE EDUCAÇÃO
}

\author{
Carmen Sylvia Vidigal Moraes*
}

RESUMO: No âmbito da temática definida para o debate e em consonância com a abordagem desenvolvida pela palestra proferida pela autora deste artigo - Educação de jovens e adultos trabalhadores de qualidade: regime de colaboração e Sistema Nacional de Educação - propõe-se analisar, em perspectiva histórica, as políticas públicas de educação destinadas a jovens e adultos trabalhadores, a partir dos primeiros governos republicanos até a atualidade, problematizando as relações entre mudança social e mudanças educacionais, a presença ou ausência dos trabalhadores nesse processo, bem como as concepções de trabalho e de educação, e a de sua relação, ordenadoras das políticas em seus diferentes momentos e conjunturas sociais.

Palavras-chave: Educação de jovens e adultos. Educação profissional. Ensino médio. Educação integrada. Mudança social e mudança educacional.

\section{YOUNG AND ADULT WORKERS' QUALITY EDUCATION: COLlaboration AND THE NATIONAL SySTEM OF EdUCATION}

\begin{abstract}
Under the theme set for the debate and in line with the approach developed by the speaker - Young and adult workers' quality education: collaboration and the National System of Education - I propose to examine, in a historical perspective, education policies for young and adult workers, from the first Republican governments to the present, discussing the relations between social change and educational changes, the presence or absence of workers in this process, as well as the conceptions of work and education, and of their relations, which orient policies at their different moments and social conjunctures.
\end{abstract}

Key words: Youth and adult education. Professional education. High school. Integrated education. Social change and educational change.

Faculdade de Educação da Universidade de São Paulo. São Paulo (SP) - Brasil.

Contato com a autora: <moraescs@usp.br> 


\section{ÉDUCATION DE JEUNES ET D'ADULTES TRAVAILLEURS DE QUALITÉ: REgime de COllaboration et Systeme National d'Éducation}

RÉSUMÉ: Dans le contexte de la thématique proposée pour le débat et en accord avec l'approche développée par la conférencière - Éducation de jeunes et d'adultes travailleurs de qualité: régime de collaboration et Système National d'Éducation -, il se propose d'analyser, dans une perspective historique, les politiques publiques d'éducation destinées aux jeunes et aux adultes travailleurs, depuis les premiers gouvernements républicains jusqu'à l'actualité, au regard des rapports entre les changements sociaux et éducationnels, de la présence ou de l'absence de travailleurs dans ce processus, ainsi que les conceptions de travail et d'éducation, qui organisent les politiques à différents moments et conjonctures sociales.

Mots-clés: Éducation de jeunes et d'adultes. Éducation professionnelle. Enseignement Secondaire. Éducation intégrée. Changement social et changement éducationnel.

\section{Introdução}

A

s reflexões a serem apresentadas pretendem contribuir, de forma complementar, com as anunciadas pela professora Margarida Machado. Sua fala, clara e concisa, é portadora do gume político necessário ao enfrentamento do quadro difícil, complexo, em que se encontram tanto a educação de jovens e adultos trabalhadores como a educação profissional, em suas diferentes etapas - formação profissional inicial e de nível médio técnico. Com essa perspectiva, a exposição está organizada em duas partes. A primeira traz ordenamentos legais - construídos desde os inícios da República -, o que possibilita levantar alguns temas e problemas que estão na base de concepções, projetos e práticas concernentes à educação de jovens e adultos (EJA) e à educação profissional em nosso país, e permite, ao mesmo tempo, apreender elementos históricos com o objetivo de discutir possíveis relações entre mudança social e mudanças educacionais no campo da denominada "educação popular". A segunda parte propõe analisar as atuais políticas públicas na área de educação e trabalho, enfatizando seus avanços e limites.

\section{Algumas lições do passado}

Antes de mais nada, é preciso esclarecer o conceito de educação popular. No Brasil, os diferentes serviços prestados à coletividade no âmbito da educação escolar, dirigidos à formação geral e à formação profissional nas diferentes etapas e modalidades da educação básica e superior, "têm origem em momentos diversos e sua criação atendeu a imposições econômicas, políticas e ideológicas distintas" (BEISIEGEL, 2009, p. 57). As práticas de "educação popular" são estudadas sob diferentes ângulos: 
na perspectiva especificamente pedagógica, econômica, dos métodos de ensino utilizados, etc., mas, como observa o professor Celso Beisiegel (2009, p. 68), é no campo da política que se esclarecem suas determinações mais significativas. Em outras palavras, "o termo 'popular' tem seu campo específico de significações em iniciativas e contextos teóricos concernentes às estruturas de dominação". Sob essa perspectiva, entendemos situar os movimentos e as políticas de educação de adultos e de formação profissional como expressão das relações do processo educativo com as estruturas de poder e dominação social.

Compreender a realidade educacional brasileira significa compreender a história de nosso país. A grande diversidade de situações educacionais ou tipos de ensino, de sua criação e das mudanças que vieram a experimentar dão forma a um quadro complexo somente apreensível a partir de sua contextualização no âmbito da especificidade da formação econômico-social brasileira, espaço social no qual convivem diferentes tempos históricos. O problema do ritmo e das formas de disseminação das relações sociais capitalistas se expressa na conformação diversa da educação escolar e das políticas governamentais que lhes dão substância, nas diferentes regiões e localidades do país. ${ }^{1}$

Levando-se em conta essa diversidade de situações, estudos realizados por Beisiegel sobre o processo de transformação dos vários tipos de ensino instituídos no país sugerem ser possível identificar duas situações definidas, duas "modalidades típicas de articulação entre mudança social e mudanças nos serviços da educação escolar" (BEISIEGEL, 2009, p. 58). Uma primeira modalidade de articulação pode ser visualizada justamente no exame das origens das ideias e tentativas de implantação da "instrução popular" no Brasil. Nesse caso, o desenvolvimento da "instrução popular" antecipa-se à existência das demandas sociais por oportunidades escolares.

No Brasil, no século passado, os republicanos viram na educação a condição para emancipar a sociedade e constituir a nacionalidade e a cidadania, para legitimar o Estado Republicano. Tais concepções, oriundas de um ideário liberal voltado à afirmação dos direitos universais de indivíduos abstratos, defendiam a educação comum para os cidadãos como direito de todos e, mais tarde, como dever de todos. Na representação costumeira desses liberais da "ilustração brasileira", o povo encontrava-se deseducado para a vida social e política, e viam-se como os principais responsáveis pela difusão das luzes, para alçar o homem comum à condição de cidadão responsável e disciplinado, integrado à sociedade que almejavam construir. Daí o caráter de antecipação da oferta educacional à emergência de sua necessidade na população, a justificativa das providências legais com vistas à imposição do exercício do direito à educação (MORAES, 2003).

Ao mesmo tempo, é importante lembrar que o processo de industrialização no Brasil não se deu nos mesmos moldes seguidos pelos países centrais do capitalismo, 
principalmente porque aqui o "novo" e o "arcaico" estabeleceram uma convivência estrutural e dinâmica (OLIVEIRA, 1972). A sociedade urbano-industrial formou-se nos quadros de uma sociedade agrário-exportadora, baseada na grande propriedade territorial e no trabalho escravo. Ao contrário do que aconteceu na Inglaterra, os movimentos de expansão do capital ocorreram em uma sociedade escravocrata em decomposição, e a implantação do capitalismo industrial não incluiu o período manufatureiro e a desagregação do artesanato. Dessa maneira, ao não atravessar o período manufatureiro, o empresário industrial local não enfrentaria imediatamente a necessidade de destruir o trabalho qualificado existente, e sim o problema de formar e qualificar a força de trabalho para o desempenho das atividades fabris. Os primeiros trabalhadores em nossas fábricas foram mulheres e crianças, e inclusive escravos, substituídos, na metade do século XIX, por imigrantes europeus, principalmente italianos e espanhóis.

Como observa F. Fernandes (1966), desde a Colônia até o final do Império, a educação escolar permaneceu privilégio de poucos. Na República, com o deslanchar das relações de produção e a universalização do trabalho livre, ocorrem mudanças na sociedade e na educação escolarizada, organizada e utilizada institucionalmente durante quatro séculos. Coube a uma facção da classe dominante, a seu núcleo republicano identificado com os interesses do capital cafeeiro, originário do Oeste Paulista, portador de projeto de mudança social, a construção de um novo padrão de sociabilidade capitalista e de uma nova escola. ${ }^{2}$

A expansão da economia cafeeira induz a uma diversificação na aplicação do capital nucleado na mercadoria café: ao desenvolvimento orgânico das relações de produção capitalista, mesmo que de maneira extremamente fragmentada. Será nos períodos de alta lucratividade média da cafeicultura que se criam as condições para que parte dos lucros seja investida em outros segmentos do complexo: bancos, estradas de ferro, indústrias, usinas. As novas fábricas passam a se localizar no Centro-Sul, principalmente em São Paulo, ocorrendo um deslocamento da produção industrial antes desenvolvida em outras regiões. O país ingressa em nova fase do processo de acumulação capitalista, e expressivas mudanças econômicas e sociais ligadas à industrialização e à urbanização ocorrem, em particular, nos grandes centros urbanos como São Paulo.

O ensino profissional foi organizado pelos republicanos históricos, como instituição privada, ainda nos tempos do Império. Entretanto, no período anterior à imigração subsidiada pelo Estado, apesar das tentativas de introdução dos cursos profissionalizantes no Liceu de Artes e Ofícios (LAO), a educação do trabalhador parece confundir-se com as aulas preliminares noturnas de alfabetização criadas, nessa época, pelos mesmos agentes sociais por meio da maçonaria. Com a vigência do Estado Republicano e após a implantação da imigração em massa, desencadeando o processo 
de desenvolvimento comercial, urbano e industrial, outros interesses e necessidades impelem à implementação de novas medidas no campo do ensino popular e profissional, quando então a qualificação técnica do trabalhador passará a ser parte indissociável de sua formação moral. Como expressão desses interesses, o LAO vai constituir-se, a partir de 1890, em escola profissionalizante dirigida a categorias bastante específicas de trabalhadores, aqueles requisitados pela indústria da construção civil: marceneiros, carpinteiros, mestres de obras.

Mais tarde, o novo governo republicano paulista, na gestão de Bernardino de Campos, faz aprovar lei reformando o ensino no estado. Considerando "de urgente necessidade dar educação à população operária", além de outras medidas, cria os cursos noturnos para "ministrar conhecimentos indispensáveis aos menores de 16 anos que por trabalharem durante o dia não podiam frequentar escolas" (art. 69 do Regimento Interno de 26/7/1894). Em 1917 existiam no estado 139 escolas e cursos noturnos, para "menores e para adultos", atendendo 7.763 alunos (ANUÁRIO DO ENSINO DO ESTADO DE SÃO PAULO, 1917, p. 282-283).

Um aspecto importante pode ser aqui apontado: alegando o precário desenvolvimento da indústria, a fragilidade das classes dominantes ou a "incapacidade" delas em propor e implantar projetos de seu interesse, algumas análises simplistas consideram a existência do ensino profissional nos moldes burgueses de preparação de mão de obra apenas a partir dos anos de 1940, com as Leis Orgânicas do Ensino. ${ }^{3}$ No entanto, o ensino profissional oficial foi organizado, em 1909, pelo governo federal, e, em 1911, pelo Governo do Estado de São Paulo, na gestão do educador escolanovista Oscar Thompson. E se o discurso legal no plano federal - da criação, por Nilo Peçanha, das 19 escolas de aprendizes e artífices nas capitais dos estados - era ainda o de assistência aos pobres, as iniciativas paulistas revelam os objetivos da burguesia emergente de institucionalizar a formação profissional de modo a qualificar trabalhadores nacionais para setores econômicos que então se modernizavam.

A República pode ser entendida como o regime da organização do mercado livre de força de trabalho, constituído inicialmente por imigrantes, com participação insignificante do elemento nacional. As greves e os conflitos dos trabalhadores contra as péssimas condições de vida e trabalho levam governos e industriais a promover a expulsão dos trabalhadores estrangeiros do país, a limitar o seu número nas fábricas e a tomar medidas para a sua substituição pelos nacionais. O ensino profissional, instituído como escola de nível primário, é visto como questão patriótica, "veículo seguro de nacionalização", voltado para a ressignificação e a valorização social do trabalho, pois o trabalho manual era considerado atividade indigna para o homem livre, branco, em sociedade de herança escravista.

Os conflitos operários - greves de 1917 e 1920 -, a conquista da jornada de 8 horas de trabalho incentivam a introdução de princípios e técnicas tayloristas nas 
empresas paulistas. O empresário Roberto Simonsen propõe, em uma conferência, a adoção da Organização Científica do Trabalho para "driblar a luta de classes e promover cooperação entre trabalhadores e patrões" (SIMONSEN, 1919). O empresário já introduzira na própria empresa, na construção de quartéis para o Ministério da Guerra, os métodos de racionalização do trabalho, assim como Francisco Ramos de Azevedo, diretor do Liceu de Artes e Ofícios e professor da Escola Politécnica, o fizera em seu escritório, no processo de construção de sobrados para os chamados barões do café, na Avenida Paulista, e de edifícios públicos, como o Teatro Municipal e a Estação da Luz, por exemplo.

Criada em 1924, a Escola Mecânica do LAO, fruto de convênio entre o governo e as companhias ferroviárias, contrata Roberto Mange (engenheiro suíço) para implementar os métodos tayloristas na organização do trabalho nas empresas fabris e desenvolver a psicotécnica, instrumento para avaliar a capacidade e a "vocação" dos trabalhadores - selecionar o "homem certo para o lugar certo". Os métodos desenvolvidos por Mange foram aplicados no LAO, e, via Instituto de Organização Racional do Trabalho (Idort), na administração pública estadual e federal. Mais tarde, foram adotados pelo Centro Ferroviário de Organização e Seleção Profissional, o qual, por sua vez, veio a se tornar o núcleo matriz dos procedimentos e programas desenvolvidos no Serviço Nacional de Aprendizagem Industrial (Senai), em 1942.

Nos anos de 1940, o ensino profissional foi marcado, no plano federal, pela Lei Orgânica (1942), orientada pelas concepções da Escola Nova paulista, sistematizadas por Fernando de Azevedo a partir do inquérito sobre a instrução pública do Estado de São Paulo, realizado em $1926 .{ }^{4}$ Ao contrário da proposta de organização da Escola Pública Unitária, presente no Manifesto dos Educadores ao Povo e ao Governo, em 1932, defendida por Anísio Teixeira e seu grupo (Paschoal Leme, entre outros), e levada à prática no Rio de Janeiro quando Anísio ocupou o cargo de diretor da Instrução Pública do Distrito Federal (1931-1935), o Ensino Técnico - promovido em nível médio - foi organizado como ramo distinto, sem canais de comunicação com o ensino secundário, e praticamente sem acesso ao ensino superior. Instituem-se duas estruturas paralelas: de um lado, o ensino médio secundário - formação geral e propedêutica aos estudos superiores, destinado a formar as "individualidades condutoras" - e, de outro, o ensino médio profissional - comercial, industrial e agrícola, para formar mão de obra qualificada para o mercado de trabalho, além do Curso Normal, para o magistério.

As modalidades não formais de formação profissional, destinadas a treinamento/aprendizagem/qualificação profissional de trabalhadores industriais, passam a ser realizadas pelo Senai, gerido até hoje pela Confederação Nacional das Indústrias, apesar de financiado com recursos públicos. ${ }^{5}$ Contrariando o projeto do Ministério da Educação e Saúde, sob a gestão de Gustavo Capanema, o Ministério 
do Trabalho vai aderir à proposta da Federação das Indústrias de São Paulo (Fiesp), cuja presidência era então exercida por Roberto Simonsen. Nessas circunstâncias, a organização do ensino profissional sob a tutela do Ministério da Educação não se concretizou. O Ministério do Trabalho e a Fiesp conseguiram implantar o sistema de educação profissional que consideravam mais conveniente, mais ajustado aos interesses empresariais e livre da interferência governamental, na forma de cursos isolados do sistema de ensino, a cargo das indústrias, como assunto ligado às demandas da produção e não a objetivos educacionais ou aos direitos dos trabalhadores.

Observa-se, portanto, que as primeiras tentativas de extensão de ensino comum a todos os adultos que não haviam frequentado a escola na idade própria, assim como o ensino profissional, atendem a características daquela modalidade típica de articulação entre mudança social e mudança educacional: promovidas pelos setores dominantes pressupõem a necessidade de uma educação para todos, têm o propósito de preparar a população trabalhadora para a realização de certas finalidades, segundo um projeto determinado de aperfeiçoamento da sociedade, atributos que conferem clareza às dimensões ideológicas e de controle social do processo educativo.

Nessa mesma categoria se incluem a Campanha de Educação de Adultos promovida pelo Ministério da Educação e Saúde, a partir de 1947, e o Programa Nacional de Alfabetização, instituído pelo Decreto n. 53.465, de 21 de janeiro de 1964. Ambos, dirigidos à massa iletrada da população, defendem a educação como direito de toda a população e vinculam-se a um projeto de melhoria da sociedade. No entanto, apesar das semelhanças que possam existir, as orientações gerais dessas iniciativas se opõem. Como afirma Beisiegel (2009, p. 68-69), ao passo que os demais movimentos educacionais conduzidos pelos intelectuais organicamente vinculados às classes dominantes "tinham em vista integrar, homogeneizar", para "transformar a situação de classe em situação de massa, de povo, de cidadão comum", o programa proposto em 1964, desenvolvido mediante a utilização do método Paulo Freire de Alfabetização de Adultos, "fazia convergirem para o processo educativo as tensões sociais e políticas que marcavam o período". A seu ver, o Programa Nacional de Alfabetização, do governo federal, assim como o Movimento de Educação de Base (MEB), os de cultura popular (MPC), os Centros Populares de Cultura (CPC) tinham em comum o propósito de estender a atuação do processo educativo às origens sociais das desigualdades que buscavam combater. Nessa medida, concordamos com o autor quando considera que as atividades dos grupos envolvidos na "educação popular" assumem significados mais definidos, uma vez "que se orientam com vistas a explicitar junto aos segmentos 'populares' a sua condição de classe e as potencialidades transformadoras inerentes a essa condição" (BEISIEGEL, 2009, p. 68).

Caminhando um pouco mais em nossa reflexão, é preciso considerar a segunda modalidade de articulação entre mudança social e mudanças na educação 
escolar. Nesse caso, a expansão das oportunidades educacionais e a transformação qualitativa do ensino decorrem das lutas sociais pela abertura de vagas. As mudanças no ensino secundário no estado de São Paulo, após 1945, constituem exemplo significativo. Como indicam os trabalhos referenciais de Beisiegel (1964, 1974, 1976, 1984, 1993, 1995, 2009) e Sposito (1984), no período que se estende do final do Estado Novo até os últimos anos da década de 1960, o crescimento da rede de escolas secundárias aparece como respostas do poder público à progressiva generalização da procura de matrículas nesse tipo de ensino.

Nessa época, ocorrem mudanças profundas nas condições de vida da região. Embora possamos considerar os anos de 1930 a 1980 como um longo período de industrialização por substituição de importações, as estatísticas mostram que a década de 1940 foi aquela em que as mudanças estruturais se fizeram mais intensas em nossa história, seguida pela década de 1930 e de 1950. A atividade agrícola recuou de uma participação de $44,6 \%$ no PIB, no início do século XX, para o porcentual de 16,9\% em 1960, ao passo que a indústria cresceu de 11,6\% em 1900 para 29,9\% em 1960 (BONELLI, 2003, apud LEAL, 2011).

Os números são expressivos no indicar as grandes transformações em curso - migrações e inversão das posições numéricas da população nas áreas rurais e urbanas, crescimento urbano e mudanças na estrutura do mercado de trabalho, "desconstrução e reconstrução de identidades coletivas, lutas de classes, de gênero e de etnias, desestruturação e reestruturação de alianças políticas e de formas de dominação, controle e resistência" (LEAL, 2011, p. 42).

Nesse período, segundo Celso Beisiegel (1964), embora a escola secundária já não apareça como condição suficiente para a realização do êxito profissional, é vista pelas populações que a procuram como condição necessária à conquista de melhores posições e empregos. E o agente político - no Executivo ou no Legislativo - surge como mediador entre as reivindicações dos habitantes e a atuação do Poder Público na área do ensino. Com o fim da ditadura Vargas e a retomada do regime político baseado no voto, as aspirações populares por melhoria de vida mediante a passagem pela educação escolar encontraram no agente político à procura de votos "um defensor intransigente na criação de mais escolas". A ação do agente político forçou a ampliação dos gastos públicos na rede de escolas secundárias. Em 1940, havia no estado 41 ginásios públicos, 3 na capital e 38 no interior. Em 1962, a rede oficial contava com 561 estabelecimentos de ensino secundário criados, 96 na capital e 465 nos municípios do interior. A rede privada, por sua vez, perde a situação predominante, passando a absorver apenas $47 \%$ dos alunos matriculados nesse ramo de ensino (BEISIEGEL, 1964).

A esse respeito, Beisiegel (1976, p. 35-36) afirma: 
A abertura das oportunidades de acesso fez com que perdessem qualquer significado as teses que definiam esse tipo de ensino como um estágio na formação das "futuras elites condutoras" do país. Encampadas pelo agente político apenas na medida em que apareciam como um elemento do processo de competição pelas posições de poder, as pressões populares acabaram, no entanto, por imprimir uma nova direção ao desenvolvimento de todo o ensino de nível médio. Embora a estrutura desse nível de ensino e mesmo os conteúdos do currículo não tenham sofrido transformações mais significativas até bem mais tarde, ainda assim a escola secundária passou de escola seletiva, como ainda a definia a legislação federal de 1942, a escola comum, tendencialmente aberta a todos. Desajustado às novas funções da escola, o currículo tradicional, embora ainda persistisse sem grandes alterações, na verdade já estava modificado: sua revisão estava implícita no processo de transformação da escola secundária em escola comum. A concretização dessa mudança curricular... era só uma questão de tempo. Mais ainda, a democratização da escola secundária implicava, também, a eliminação dos antigos ramos do ensino de nível médio e sua unificação em estabelecimentos destinados à formação geral de todos. (Grifos meus)

O autor ressalta que as inovações introduzidas na legislação escolar em 1961, com a Lei de Diretrizes e Bases, ou mesmo dez anos depois, com a Lei de Reforma do Ensino de Primeiro e Segundo Grau, “já estavam de alguma forma realizadas na evolução de fato do atendimento escolar, pelo menos nas áreas urbanas das regiões mais desenvolvidas".

A legislação escolar no período estudado passa a assumir orientação inequivocamente democratizadora. A LDBEN de 1961 expressa a tendência de eliminar os diferentes tipos de escola de nível médio ao buscar consolidar um núcleo comum de disciplinas obrigatórias no currículo das diferentes escolas de ensino médio. Embora não tenha definido o desenvolvimento de um padrão de educação nacional, a lei eliminou "parte das diferenças entre os ramos do ensino médio, atribuiu às diversas escolas a denominação geral de ginásios - secundário, industriais, comerciais e agrícolas" - e, não obstante persistirem os diferentes tipos de estabelecimentos, "exigia-se, como antes, a adaptação curricular para efeito de transferência”" (BEISIEGEL, 1976, p. 36).

É importante assinalar, também, as várias experiências surgidas na época, os "ginásios voltados para o trabalho", as escolas experimentais, os ginásios vocacionais, os ginásios "único-pluricurriculares", e, no final dos anos de 1960, os "grupos escolares-ginásios", os quais foram instituídos em São Paulo, "como projeto piloto de uma ampla experiência voltada à integração progressiva do ensino primário e do primeiro ciclo da escola de nível médio" (BEISIEGEL, 1984, p. 398). Assim, para o autor, tais ensaios de novas modalidades de organização escolar podem ser vistos como "respostas institucionais para tendências claramente delineadas na evolução dos serviços educacionais, pelo menos nas regiões mais desenvolvidas do país", e que serão formalizadas, um pouco depois, com a Lei n. 5.692, de 11 de agosto de 1971. A Lei de Reforma do Ensino fixou, a princípio, a obrigatoriedade do ensino comum de oito anos, e integrou o nível primário e o primeiro ciclo do nível médio, 
que passaram a constituir "modelo único de escola internamente flexível e adaptável às peculiaridades regionais e locais".

Sobre a integração entre o ensino primário e o ensino de nível médio, Anísio Teixeira (1976, p. 72) fará uma interessante observação, anterior à promulgação da LDBEN, em 1961:

Com o progresso do espírito democrático, que é, acima de tudo, um espírito de unificação e de destruição dos dualismos intelectuais, que se não encobrem disfarçam os dualismos sociais, o povo resolveu ingressar não na escola prática, que a priori se lhe destinou, mas na acadêmica, com tanto maior razão quanto se pretende que seja esta a escola de formação da elite, e o povo não vê razão de ele também não fazer elite. Além do mais, tal escola acadêmica nunca foi uma escola cara e por isso pode existir e até multiplicar-se em períodos de grande pobreza social. [...] A esperança - sem paradoxos - está nessa mesma expansão. Buscada como privilégio, deixará de ser tal, em virtude de sua própria generalização e, nesse dia, um novo processo terá início - o de sua transformação na escola moderna de nível médio, que se há de criar também no Brasil, em virtude mesmo do seu progresso real.

As esperanças de Anísio Teixeira, no entanto, confirmaram-se apenas em parte. O padrão dualista do ensino irá permanecer em outros moldes. Se, de um lado, como resultado das pressões populares houve a integração do ensino primário ao primeiro ciclo do ensino médio, superando-se uma das barreiras verticais do acesso ao ensino secundário, por outro, as barreiras seletivas no plano vertical e horizontal, transferidas para o segundo ciclo do ensino médio, apesar de amenizadas na LDB de 1961, persistiram na Lei n. 5.692, de 1971.

A Lei n. 5.692/71 introduziu grande mudança formal: os cursos técnicos profissionais, organizados como ramos de ensino médio, com legislação e órgãos governamentais próprios, fundem-se em um curso único de nível médio - ou de $2^{\circ}$ grau, segundo a nova nomenclatura. De acordo com essa lei, o ensino de todas as escolas de $2^{\circ}$ grau será técnico. A distinção deixa de ser feita entre ramos de ensino para ser realizada entre currículos orientados para habilitações profissionais. O curso técnico industrial foi o modelo implícito na organização do novo ensino médio profissionalizante. Entre as 52 habilitações correspondentes a técnicos de nível médio, 32 referiam-se ao setor industrial, indicando a ênfase que devia ser dada às ocupações desse setor de atividades (CUNHA, 1977).

Em 1965 - após o golpe militar e findo o período das esperanças desenvolvimentistas -, ao "situar a qualificação do trabalho na expansão e consolidação do capitalismo na sociedade brasileira contemporânea", Luiz Pereira (1965, p. 290-293) define as "relações dinâmicas entre instituições escolares e estruturas sociais inclusivas", como a problemática central do pensamento pedagógico brasileiro. Formula, então, a hipótese de que no processo crescente de burocratização e racionalização 
da organização escolar, que substituíra as práticas de participação social, a atuação do Estado, de empresários e educadores tendia "a uma instrumentalização cada vez maior das instituições escolares".

A economia da educação consistia na teorização dessa instrumentalização, "preocupada com a rentabilidade dos dispêndios realizados ou realizáveis com a educação", que aparece, então, concebida como "instrumento de produção do 'capital humano', e as escolas como empresas ou 'locii' dessa produção". Dessa forma, "enfoque, tratamento, conclusões e recomendações" acerca das relações entre educação e subdesenvolvimento-desenvolvimento

[...] encontram-se sempre na linha da "economia da educação": não se cuida dos homens, mas da força de trabalho; não se trata da constituição de homens historicamente determinados, mas da elaboração de um fator de produção necessário - força de trabalho nos vários níveis e tipos de qualificação técnica. E, assim, reencontramos o tecnicismo economicista predominante em seu caráter abstrato, nas formulações sobre o tema e em sua insuficiência. (PEREIRA, 1965, p. 291)

As consequências da implementação dessa política educacional moldada nas concepções ideologizadas da "Teoria do Capital Humano" - que reduz a educação a mero fator de produção - foram dramáticas. Além de não ter provocado mudanças no caráter elitista da educação brasileira, a reforma implicou a descaracterização e maior desqualificação do ensino médio. O empobrecimento dos currículos escolares com a retirada e o esvaziamento dos conteúdos de formação geral, imprescindíveis para a compreensão crítica da realidade social, e o fracasso na realização da pretendida formação técnica só vieram reforçar a dicotomia entre a educação para a "elite" e a educação para o trabalhador. Sem se constituir em escola profissional, a escola pública de $2^{\circ}$ grau deixa de ser também uma escola propedêutica, preparatória para os cursos superiores. A escola pública destinada a amplos setores da população trabalhadora está, assim, esvaziada de suas atribuições sociais de socialização do conhecimento. Ao mesmo tempo, as escolas das redes de ensino técnico - as estaduais e a federal - continuaram a funcionar, adquirindo uma qualidade diferenciada, propiciada em parte pelo caráter seletivo de acesso dos alunos por meio do "vestibulinho" e, em parte, pela relativa autonomia de sua gestão. Manifesta-se, dessa forma, na especificidade histórica da sociedade brasileira, uma dualidade no ensino invertida: a escola pública regular, propedêutica, consiste na modalidade de maior acesso à população pobre, ao passo que a escola técnica pública de nível médio se torna seletiva, destinada a menor número.

As mudanças econômicas, políticas, jurídicas e institucionais conduzidas pelo regime autoritário resultaram em profundos desajustes na sociedade, transformando grande parcela das conquistas no campo da educação escolar "em mentiras", 
como afirma Sposito (2010, p. 20-21). De acordo com a autora, "parte dos problemas relativos ao acesso à educação pública manteve-se sem solução e a maioria da população apenas conquistou o direito de entrar numa escola que, em pouco tempo, se encarregaria de sua exclusão".

A forte repressão desencadeada em todo o país a partir do AI-5, em 1968, iria desacelerar o ímpeto organizativo nos bairros, nos anos de 1970. Mas, ao longo da década, novos movimentos sociais se espalharam em São Paulo. E, então, "uma longa e subterrânea tradição organizativa no bairro iria alimentar e 'dialogar' com esses novos militantes e organizações" (LEAL, 2011, p. 399).

Apesar dos mecanismos de controle social e do quadro de participação restrita, os movimentos sociais radicados nos bairros da cidade de São Paulo mobilizaram-se para tentar garantir ou impor os seus direitos de cidadania. Estudos realizados sobre os movimentos das Sociedades de Amigos de Bairro (SABs) e seus organismos articuladores, sobre os das Comissões Eclesiais de Base (CEBs), organizadas um pouco mais tarde, e sobre grupos de mães, grupos de moradores, existentes em São Paulo nesse período, indicam que encaminharam, no âmbito de suas reivindicações pela melhoria das condições de vida e trabalho, diferentes demandas por educação escolar: pela criação de creches, parques infantis e escolas de primeiro e de segundo graus, organização de cursos noturnos, pela ampliação da rede física escolar e construção de novos prédios (o número de alunos por estabelecimento na rede municipal passara de 355 em 1966 para 962 em 1974, por exemplo) (SPOSITO, 2010, p. 85).

Utilizando-se de diferentes estratégias na relação com as administrações públicas, os moradores da periferia lutaram para dar visibilidade às suas necessidades. Os movimentos pela educação acompanhavam os movimentos contra a carestia, pela saúde e pela moradia. Os problemas de acesso à escola passam a expressar, na segunda metade dos anos de 1970, reivindicações para a instalação de cursos noturnos em escolas públicas, tanto de primeiro como de segundo grau (SPOSITO, 2010, p. 93). Tais demandas eram, algumas vezes, associadas a denúncias a respeito de jovens impedidos de estudar em razão das condições de trabalho a que eram submetidos (A Gazeta da Zona Norte, 23/1/1977, apud SPOSITO, 2010, p. 93).

Ampliam-se nos anos de 1980 as lutas pelo ensino supletivo público, tradicionalmente nas mãos de particulares (até final dos anos de 1970, só o Ginásio Experimental da Lapa mantinha um curso supletivo estadual). Já não é suficiente a garantia de acesso ao primeiro grau, é preciso também "conquistar a continuidade e, mais do que isso, o direito à volta ao estudo às populações excluídas da escola pública" (SPOSITO, 2010, p. 105).

O Centro de Clubes de Mães, movimento organizado na região de PiritubaPerus (Zona Norte), que reunia vários grupos de mães, realizou, em 1981, pesquisa 
em 48 escolas das redes estadual e municipal, quando foram consultados diretores, alunos e moradores de 70 vilas, integralizando um total aproximado de 2.500 pessoas. O levantamento concluiu pela insuficiência de escolas, diurnas e noturnas, de segundo grau, diante dos egressos da oitava série, indicando que a evasão e o abandono dos estudos se deviam à incompatibilidade entre os horários de trabalho e de entrada em aula. Apontava, ainda, a falta de condições de trabalho dos professores que lecionavam na região. Propunha a criação de cursos profissionalizantes de segundo grau, particularmente os de contabilidade, secretariado, técnico e mecânica, pois $96,5 \%$ dos 2.497 estudantes de sexta, sétima e oitava séries pretendiam cursar a escola profissionalizante, de maneira a possibilitar a esses jovens estudar e, ao mesmo tempo, trabalhar e ajudar no orçamento doméstico. Estudo da Fundação Carlos Chagas, na mesma época, mostrava que, dos 48.095 jovens de 15 a 18 anos de idade, apenas 5.617 estavam matriculados no segundo grau, isto é, $11,6 \%$, com maioria de 80\% em escola pública (SPOSITO, 2010, p. 106-107).

Nesse ponto, é possível reafirmar algumas possíveis conclusões do primeiro tópico da exposição: a presença e importância das forças populares nos avanços introduzidos na organização escolar em direção à democratização das oportunidades educacionais, bem como o seu efeito nas mudanças curriculares e na normatização legal. Embora tais acontecimentos, lidos como conquistas sociais pelo professor Celso Beisiegel, possam ser questionados por alguns, em face dos limites impostos pela estrutura desigual da sociedade de classes à democratização da vida social, não há como ignorar - do ponto de vista histórico e sociológico - a presença fundamental dos setores populares urbanos na ampliação dos conteúdos democratizadores da prática educacional, os quais por sua vez podem contribuir, como argumenta o autor, para a contenção e, mesmo, para a superação desses limites.

A rápida digressão realizada a partir dos trabalhos de Beisiegel busca denotar a importância de suas pesquisas, entre as poucas a indicar as populações urbanas como sujeitos no processo de construção histórica da educação brasileira. Como ele enfatiza, "a participação popular na determinação de suas condições de vida tem implicações relevantes, inclusive do ponto de vista de uma política popular" (BEISIEGEL, 1995, p. 411).

Almejamos, no entanto, não apenas indicar a presença dessa participação popular, mas consideramos fundamental qualificar a participação desses setores populares, os moradores de periferia. A esse respeito, importa observar que os bairros periféricos da Grande São Paulo e de outras metrópoles brasileiras foram vistos até os anos de 1980, aproximadamente, como espaço social extremamente heterogêneo, território das "classes populares", conceito algo controvertido que, segundo José Álvares Moisés (1982), designaria operários industriais, assalariados de bancos e comércio, baixa burocracia estatal, profissionais liberais, ou, segundo Eunice Durham 
(1988, apud LEAL, 2011), operários, trabalhadores por conta própria, biscateiros, empregadas domésticas, pequenos funcionários públicos.

De acordo com Leal (2011), os autores que refletiram sobre as atitudes e a formação da consciência da classe trabalhadora brasileira a partir de um prisma mais tradicional, privilegiando sua inserção no processo produtivo, enxergaram na periferia a heterogeneidade, vendo nessa heterogeneidade a chave para explicar a adesão dessas populações ao populismo que, entre outras coisas, lhes conferiria, no plano da política, uma identidade que elas seriam incapazes de construir nas relações sociais de que participavam.

Esses estudos sociológicos, balizados pela noção de modernização, sustentados em uma suposta divisão estrutural do país entre o atraso rural e o progresso urbano, viam a migração como a passagem de sociedades e culturas tradicionais e arcaicas para a cidade, espaço do desenvolvimento industrial e do moderno. Dessa forma, a urbanização e a industrialização representariam para os migrantes um estágio mais avançado de desenvolvimento e uma possível ascensão social e econômica. Entretanto, para essa sociologia, as primeiras gerações de migrantes, empregadas em larga medida em trabalhos que exigiam pouca formação profissional nas modernas fábricas e no setor de serviço das grandes cidades, estariam impregnadas por resíduos culturais tradicionais e mostrariam precário ajustamento a essa nova realidade, não se identificando com a condição operária, numa espécie de adaptação apática. Considerados, portanto, passivos, os novos operários migrantes seriam facilmente manipulados pela ação dos políticos populistas carismáticos (FONTES, 2008). Tal análise foi amplamente difundida, tornando-se uma espécie de senso comum acadêmico.

No entanto, é possível observar atualmente um grande esforço por parte dos historiadores sociais no sentido da ampliação e da análise de temas e aspectos da vida dos trabalhadores. Não apenas o movimento operário organizado é objeto de atenção, mas as diversas dimensões da classe operária, as relações sociais de sexo, as relações familiares, as formas de lazer e sociabilidade, entre outros aspectos, têm sido valorizadas. Para muitos dos historiadores sociais e do trabalho, o desafio consiste em relacionar, combinar a abordagem dos temas clássicos - sindicatos, partidos políticos, greves, relações de trabalho nas empresas - com a perspectiva mais ampla da diversidade de experiências da classe operária (FONTES, 2008).

Esses "jovens" historiadores - como Fontes e Leal aqui citados - estudam os bairros, as localidades, "não apenas como um lugar, mas também como um conjunto de relações sociais" (FONTES, 2008, p. 22). Tal abordagem - segundo Fontes - tem sido decisiva para o entendimento dos laços, das redes de relacionamento entre os trabalhadores e sua ação coletiva. Suas pesquisas procuram analisar essas 
redes sociais criadas pelos trabalhadores "tanto no processo de migração quanto em seus locais de trabalho e moradia" (idem, ibid., p. 32), mostrando, ao contrário dos estudos anteriores, que, de fato:

[...] em vários momentos, os trabalhadores e suas entidades conseguiram unificar reivindicações, ultrapassando na prática as fronteiras entre as lutas nas fábricas e nos bairros. Esta suposta divisão entre trabalhador e morador (enfatizada por aqueles autores) foi, na verdade, muitas vezes superada por uma ação política baseada em uma noção de classe muito mais ampla, incluindo as várias dimensões da vida dos trabalhadores e trabalhadoras, em São Paulo. (FONTES, op. cit., p. 280)

A esse respeito, pesquisa desenvolvida entre 1974 e 1975, em São Paulo, envolvendo 50 SABs, concluiu que a categoria mais encontrada entre os membros da diretoria era a de operários industriais, com 18\%, seguida por trabalhadores por conta própria (motoristas, pedreiros, pintores, barbeiros), com 16,5\%, vindo depois os comerciantes, em $14,5 \%$, e, finalmente, comerciários, com $12 \%$. Do total dos filiados, $56 \%$ são classificados como pertencentes às classes populares (marceneiros, motoristas, sapateiros, operadores de máquinas e torneiros mecânicos), 35\% à "classe média" e 8\% aparecem sem informação (GOHN, 1982, p. 119-120).

Nessa direção, Leal (2011, p. 115) pretende "substituir a ideia de uma periferia ocupada por uma massa heterogênea de migrantes, por meio dos quais os operários se 'diluíam"', na condição de "massa", de "morador" ou de "cidadão pobre", pela visão de uma periferia "em que se registrava uma forte presença operária, conjugada com outras classes e frações de classes. Nesse meio popular, a experiência operária e sindical era uma referência material e simbólica forte". Assim, a massa desarticulada, manipulada pelo Estado ou pelas lideranças políticas, passa a ser entendida "como uma classe que, no interior de condições que não escolhe, é capaz de fazer sua própria história, tanto quanto de ser feita por esta" (MATTOS, 2011, p. 27). Nesta perspectiva, os trabalhadores constituíram alianças, organizações, programas para enfrentar a questão trabalhista, da carestia, da moradia, da educação e da representação política a partir do ponto de vista dos interesses dos operários e populares.

Esse é o ponto de vista que abraçamos ao analisarmos as duas formas de relação entre movimento social e educacional: os trabalhadores, por meio de sua atuação, organizações, movimentos e redes sociais, contribuíram decisivamente para a construção da educação escolar no país, seja em termos da ampliação/democratização das oportunidades escolares, seja em termos da construção de concepções/orientações que ordenam os conteúdos e métodos de ensino.

Finalizando nossas reflexões históricas, ainda no âmbito das iniciativas de educação popular, é importante caracterizar a existência de projetos educacionais orientados por movimentos de trabalhadores, de acordo com seus interesses de 
classe. Entre eles, as Escolas Modernas organizadas por grupos anarquistas, em particular a Escola Moderna n. 1, dirigida pelo educador João Penteado e situada no bairro operário do Brás, na cidade de São Paulo, experiência escolar libertária que alcançou maior duração - de 1912 a 1919, quando foi fechada pelo governo paulista -, constituem exemplos referenciais de programa cultural e educacional de combate à escola capitalista, e incorporam as contribuições de Paul Robin sobre educação integral, e os métodos do ensino racional desenvolvidos nas escolas de Francisco Ferrer Guardia, em Barcelona (MORAES; CALSAVARA; MARTINS, 2012).

A concepção de educação integral formulada por Robin está ligada à história do movimento revolucionário do século XIX e à participação do educador nos congressos da I Internacional dos Trabalhadores, em Lausane (1867) e Bruxelas (1868), onde apresenta o "Programa de Ensino Integral", aprovado pelos participantes, inclusive por Karl Marx (LUIZETTO, 1986, 1987). Na concepção de educação integral defendida no movimento anarquista por Proudhon, Bakunin e Kroptkin, contrária à existência de dois tipos de ensino - um "aprimorado", reservado aos burgueses, e outro "simplificado", destinado aos trabalhadores, que expressa a dominação de classe -, Paul Robin irá enfatizar, na apreensão de seu significado, a existência de três dimensões, necessariamente integradas: física, moral e intelectual. Francisco Ferrer Guardia, na direção das formulações de Robin, defende a educação integral para possibilitar "o pleno desenvolvimento de todas as capacidades do indivíduo", "integrando o trabalho manual e o intelectual" (FERRER GUARDIA, 1978). Nesta perspectiva, propõe a utilização de métodos ativos, a coeducação social e de sexo, e a integração da escola com seu entorno físico e social (MORAES et al., 2011).

Dando continuidade à luta pela educação integral, integrada ou unitária, no país, temos mais recentemente, entre as escolas experimentais, a implementação dos Ginásios Vocacionais no estado de São Paulo, no final da década de 1950 até o início dos anos de 1970, reunindo um grupo de educadores militantes da educação democrática interessados em viabilizar a apropriação, pela classe trabalhadora, do saber socialmente constituído. Liderados pela educadora Maria Nilde Mascellani, apresenta entre os seus protagonistas um professor proveniente da escola libertária de João Penteado, o professor Luiz Contier - expressão concreta dos laços que unem no tempo tais iniciativas emancipatórias de educação. A proposta de currículo integrado, o trabalho como princípio educativo e os recursos pedagógicos do estudo do meio na aproximação entre escola e cidade (polis), a participação coletiva, a autogestão e a autoavaliação conformam o Ginásio Vocacional em sua tentativa de construção da escola média unitária - proposta que, como pretendemos indicar, faz parte das lutas do movimento operário desde o século XIX.

Por fim, como herdeiras de todas essas iniciativas e daquelas desenvolvidas na clandestinidade, no combate à ditadura civil-militar, encontram-se as lutas pela 
educação integrada na década de 1980 e 1990, realizadas pelos movimentos sociais, duramente disputadas no processo de formulação da Carta Constitucional e da LDBEN, e amadurecidas na resistência às políticas neoliberais. Os ajustes da economia brasileira ao novo contexto econômico são acompanhados da presença de organismos internacionais que passam a orientar as reformas na educação em termos organizacionais e pedagógicos. As demandas da sociedade organizada foram, como no período ditatorial, substituídas por medidas produzidas por especialistas e tecnocratas, geralmente assessores desses organismos multilaterais.

Naquele momento, trabalhadores organizados discutiram e formularam sua concepção de formação profissional como "parte de um projeto educativo global e emancipador", como "patrimônio social", como educação pública, complementar à escola básica, devendo "estar integrada ao sistema regular de ensino", posições aprovadas em sua Resolução n. 14, no 5ํㅡㄹ Congresso Nacional da CUT, em 1995. A Central irá promover, pela primeira vez em sua história, projetos de educação associando elevação de escolaridade e qualificação profissional: os projetos "Integrar", da Confederação Nacional dos Metalúrgicos (CNM/CUT), e "Educação de trabalhadores por trabalhadores", realizado por sindicatos da CUT pela Base, de seis diferentes categorias em seis cidades do Estado de São Paulo, projetos que contaram com a orientação das professoras Maria Nilde Mascellani e Cecília Guaraná, ambas participantes dos referidos Ginásios Vocacionais.

As ações educativas dirigidas a jovens e adultos não reduziam os seus objetivos unicamente à dimensão profissional, mas visavam à conquista da autonomia dos trabalhadores em relação aos poderes econômicos e políticos. Os projetos de Ensino Médio Integrado, da educação profissional integrada à educação básica seja voltados para a idade adequada, seja nas modalidades EJA - foram construídos em lutas, encontros e fóruns do movimento popular, sindical e de entidades representativas de educadores da escola básica e da universidade. Tais propostas contrapunham-se às reformas promovidas pelo Governo Fernando Henrique Cardoso, as quais, moldadas, em geral, pelas orientações do Banco Mundial (Bird), além de focar o atendimento no ensino fundamental para a idade própria em detrimento de outras etapas da educação básica e, em particular, da EJA, propõem adequar o ensino às novas demandas econômicas, reformulam o ensino técnico, criam o Sistema de Educação Profissional, e, dessa maneira, aprofundam o dualismo estrutural no ensino médio e reforçam o caráter compensatório e assistencialista atribuído à formação profissional continuada.

As reivindicações pela escola unitária, pelo Ensino Médio Integrado, apresentadas ao Governo Lula e discutidas no início de sua gestão em seminários nacionais organizados pelos Ministérios da Educação e do Trabalho, levam o governo a emitir novo Decreto (n. 5.154/04), que substitui a medida anterior e permite reintegrar a 
educação profissional técnica ao ensino médio. A medida impulsionou o Ministério da Educação (MEC) a promover iniciativas que propiciassem o amadurecimento de orientações dirigidas à superação organizacional e pedagógica da separação entre formação geral e técnica, entre trabalho, cultura, ciência e tecnologia. É o caso do Programa Nacional de Integração da Educação Profissional com a Educação Básica na modalidade de Educação de Jovens e Adultos, o Proeja e o Proeja FIC (Decretos n. 5.478/2005 e n. 5.840/2006, Documentos-Base - MEC/Setec, 2007).

\section{Segunda parte: desafios das políticas atuais}

Não nos deteremos aqui nos avanços representados pelo Proeja no sentido da construção de uma política de Estado de educação pública, democrática, emancipatória e, portanto, de qualidade social, para os 80 milhões de brasileiros que não concluíram a escolaridade na chamada idade própria. Importa apenas afirmar a importância do Proeja FIC, que vem suprir a ausência histórica, em nosso país, de ensino que integre formação geral e formação profissional na escola básica de nível fundamental, possibilitando a construção de percursos formativos sustentados na concepção de eixos tecnológicos e a superação dos limites de uma formação restrita orientada pela Classificação Brasileira das Ocupações (CBO) (MORAES, 2006; MORAES; ALAVARSE, 2011 ).

Infelizmente, como se sabe, o Proeja e o Proeja Fic permaneceram na forma de programas e não se efetivaram como políticas de Estado. Além dos sérios problemas enfrentados na sua operacionalização, ${ }^{6}$ encontram-se gravemente ameaçados, neste momento, por projetos privatizantes, contrários ao ensino público e à educação integrada. É o caso do Programa Nacional de Acesso ao Ensino Técnico e Emprego (Pronatec) (Lei n. 12.513/11), que expressa o recrudescimento da disputa política no âmbito governamental e um claro retrocesso aos tempos do Decreto n. 2.208/97, instituído no Governo Fernando Henrique Cardoso.

Identificado com interesses de grupos empresariais específicos, o Pronatec propõe a adequação funcional do aluno ao mercado e induz os estados a atuarem no ensino médio concomitante à educação profissional, em "parceria" com o Sistema "S" e, com bolsas financiadas aos alunos pelo governo federal, por meio de nova linha de crédito do Banco Nacional de Desenvolvimento Econômico e Social (BNDES) (MORAES; ALAVARSE, 2011). De acordo com esse programa, expandir a oferta de financiamento estudantil à educação profissional técnica de nível médio significa promover a compra de vagas em instituições privadas. Além da Bolsa-Formação destinada aos estudantes e concluintes do ensino médio público, o programa ainda comporta duas outras modalidades de bolsa, com oferta de cursos de Formação Inicial e Continuada/FIC, para trabalhadores beneficiários do seguro-desemprego, e, 
atendendo o público dos programas de inclusão social, especialmente o Bolsa-Família (Lei n. 12.513, de 26/10/2011, e Medida Provisória n. 593, de 5/12/2012).

É importante salientar a mudança ocorrida no enquadramento institucional do Sistema "S", que passa a integrar o sistema federal de ensino, mantendo, porém, autonomia para a criação de escolas e a oferta de cursos e programas de educação profissional e tecnológica (MP n. 593/12). Observa-se, portanto, que a lei vem facilitar "o repasse de recursos diretamente sem a necessidade de realização de convênios ou de seguir as diretrizes das políticas públicas da Educação Profissional Tecnológica, em razão da permanência de sua autonomia pedagógica, financeira e administrativa" (RODRIGUES; SANTOS, 2012, p. 11). ${ }^{7}$

O Pronatec vem se consolidando como uma das principais políticas do atual governo, à revelia dos avanços sociais e da qualidade educacional traduzidas na concepção do Ensino Médio Integrado em seus diferentes tipos e modalidades, definidos nas Diretrizes Curriculares Nacionais do Ensino Médio (Parecer CNE/CEB n. 5, de 4/5/2011, e Resolução n. 2, de 30/1/2012). Sustentado nas concepções economicistas da Teoria do Capital Humano e baseado em um suposto "apagão" de mão de obra, o Pronatec é hoje política emblemática do protagonismo atribuído, pelo governo federal, às instituições privadas na oferta dos cursos de educação profissional e tecnológica. Mas, por sua amplitude, o programa e a lógica do privado incidem sobre as escolas públicas de educação básica e na oferta pública de EJA, não só privando-as do financiamento público necessário à sua expansão e qualidade, mas, sobretudo, no que diz respeito às formas de gestão, às concepções de ensino e avaliação e, no caso da formação profissional, no sentido e na natureza da certificação profissional. Os riscos dessa ingerência no agravamento de distorções nos sistemas educativos brasileiros são evidentes, aprofundando práticas excludentes na educação e no trabalho, e impedindo o fortalecimento e a ampliação da escola unitária e democrática.

Como bem coloca Antônio Gramsci (2000, v. 2), em suas considerações sobre os intelectuais e a construção da nova hegemonia cultural, uma das estratégias políticas, no processo de fazer avançar a luta democrática, consiste em repetir, repetir incansavelmente os argumentos e as justificativas. Com essa perspectiva, no processo de resistência à privatização e em defesa da escola pública, consideramos imprescindível insistir na relevância social e política de um projeto estratégico de educação básica integrada à educação profissional na modalidade EJA, sob a referência de uma política de Estado, o que impediria que as políticas educacionais ficassem a reboque dos governos - tanto federais quanto estaduais/municipais - e de suas vinculações partidárias, promovendo a permanência/perenidade dessas políticas e a sua concretização/operacionalização no âmbito do pacto federativo. Nessa direção, a consolidação da concepção sistêmica da educação, a ser concretizada por estados e 
municípios, que valoriza conjuntamente os níveis e as modalidades educacionais, a partir da realização de políticas públicas universalizantes, deve ter como horizonte a completa integração do Proeja ao Sistema Nacional de Educação (MORAES; ALAVARSE, 2011).

A ampliação e a efetivação do direito à educação pública, de qualidade, a todos os brasileiros, luta histórica dos movimentos sociais populares, das entidades científicas e sindicais de trabalhadores, manifestam-se hoje como vontade coletiva não só pela implementação dos avanços conquistados no Plano Nacional da Educação 2011-2020, ainda não aprovado, como pela ampla divulgação das Diretrizes Curriculares Nacionais do Ensino Médio nas escolas, e, sobretudo, na utilização da tribuna da Conferência Nacional de Educação (Conae), de suas conferências estaduais e municipais, nos diferentes espaços sociais em que nossa voz possa alcançar e ressoar.

\section{Notas}

1. A noção de formação econômico-social em Marx e Lenin, na interpretação de H. Lefebvre (1957, p. 248), significa que "as forças produtivas, as relações sociais, as superestruturas (políticas, culturais) não avançam igualmente, simultâneas, no mesmo ritmo histórico". A esse respeito, consultar Martins (1996).

2. A análise relativa à história da educação no final do Império e nos anos iniciais da República, em particular no estado de São Paulo, baseia-se no trabalho da autora, publicado em 2003.

3. Esse esquema simplista de análise leva a interpretações que definem o Estado anterior a 1930 como estritamente vinculado a interesses da chamada, equivocadamente, aristocracia fundiária contra os interesses da burguesia industrial, além de tomar essa data como marco divisor numa suposta passagem do pré-capitalismo ao capitalismo. Sobre essa questão, ver Martins (1979).

4. O inquérito foi promovido por O Estado de S. Paulo, em 1926, e dirigido por Fernando de Azevedo como parte de uma campanha desencadeada pelo jornal para a realização de uma reforma educacional. Foi publicado em 1937, em sua primeira edição, e depois, em 1957, pela Editora Melhoramentos, com o título: A educação na encruzilhada. Sobre o assunto, ver Moraes (2003).

5. O Sistema "S" é sustentado com recursos públicos desde 1942, contribuição social com base no desconto de $2,5 \%$ sobre a folha de pagamentos das empresas, embutidos no custo das mercadorias e repassados aos consumidores, cuja arrecadação em 2010 ultrapassou R \$ 10 bilhões.

6. Análise sobre as dificuldades de operacionalização do Proeja encontra-se em Moraes e Alavarse (2011).

7. É importante notar as semelhanças entre os procedimentos do Pronatec e os adotados pelo Programa Intensivo de Preparação de Mão de Obra (Pipmo), criado em 1963 pelo governo federal, mas reformulado em seus objetivos após o golpe militar, via Portaria Ministerial n. 46/1964. A execução do programa se daria por treinamento desenvolvido nas empresas, por cursos intensivos e regulares em escolas técnicas e industriais das redes federal e estaduais, pelos centros de formação do Senai, por cursos volantes, e por correspondência, por aprendizagem programada, seminários, pesquisas e trabalhos práticos. Mais tarde, o Decreto n. 70.882, de 1972, amplia o âmbito de atuação do programa para todos os setores da economia, e, em 1973, o Movimento Brasileiro de Alfabetização (Mobral) firma convênio com o Pipmo, cedendo-lhe recursos significativos para que realizasse "treinamento profissional" dos alunos depois de alfabetizados. Em 1974, provavelmente por sugestão do Senai e do Senac, que participavam de comissões do Ministério da Educação, 
teve sua vinculação transferida para o Ministério do Trabalho. Extinto em 1982 (Decreto n. 87.795, de 11/11), seu patrimônio foi transferido para o recém-criado Serviço Nacional de Aprendizagem Rural-Senar (CUNHA, 2000).

\section{Referências}

BEISIEGEL, C. Ação política e expansão da rede escolar. Pesquisa e Planejamento, São Paulo, n. 8, 1964.

BEISIEGEL, C. Estado e educação popular. São Paulo: Pioneira, 1974.

BEISIEGEL, C. A reforma e a qualidade do ensino. In: NAGLE, J. (Org.). Educação brasileira: questões da atualidade. São Paulo: Edart, 1976.

BEISIEGEL, C. Considerações a propósito de um projeto educacional. São Paulo em Perspectiva, São Paulo, v. 7, n. 1, jan./mar. 1993.

BEISIEGEL, C. Educação e sociedade no Brasil após 1930. In: FAUSTO, B. (Org.). O Brasil republicano: economia e cultura (1930-1964). Rio de Janeiro: Bertrand Brasil, 1995. p. 383-416.

BEISIEGEL, C. Cultura do povo e educação popular. In: BARROS, G.N.M. (Org.). Celso de Rui Beisiegel: professor, administrador e pesquisador. São Paulo: Edusp, 2009. p. 55-69.

CUNHA, L.A. A política educacional no Brasil e a profissionalização do ensino médio. Rio de Janeiro: Eldorado, 1977.

CUNHA, L.A. O ensino profissional na irradiação do industrialismo. São Paulo: Unesp; Brasília, DF: Flacso, 2000.

FERNANDES, F. Educação e sociedade no Brasil. São Paulo: Dominus-Edusp, 1966.

FERRER GUARDIA, F. La escuela moderna. Barcelona: Tusquets, 1978.

FONTES, P. Um Nordeste em São Paulo: trabalhadores migrantes em S. Miguel Paulista (1945-66). Rio de Janeiro: FGV, 2008.

GOHN, M.G. Reivindicações populares urbanas. São Paulo: Cortez, 1982.

GRAMSCI, A. Os intelectuais. O princípio educativo. Jornalismo. In: GRAMSCI, A. Cadernos do cárcere. Ed. e trad. Carlos Nelson Coutinho. Rio de Janeiro: Civilização Brasileira, 2000. v. 2.

LEAL, M. A reinvenção da classe trabalhadora (1953-1964). Campinas: Unicamp, 2011.

LEFEBVRE, H. La pensée de Lénine. Paris: Bordas, 1957. 
LUIZETTO, F. O movimento anarquista em São Paulo: a experiência da Escola Moderna n. 1(1912-1919). Educação E Sociedade, Campinas, v. 24, p. 18- 47, ago. 1986.

LUIZETTO, F. As utopias anarquistas. São Paulo: Brasiliense, 1987.

MARTINS, J.S. O cativeiro da terra. São Paulo: Ciências Humanas, 1979.

MARTINS, J.S. As temporalidades da história na dialética de Lefebvre. In: MARTINS, J.S. (Org.). Henri Lefebvre e o retorno à dialética. São Paulo: Hucitec, 1996.

MATTOS, M.B. Prefácio. In: LEAL, M. A reinvenção da classe trabalhadora (1953-1964). Campinas: Unicamp, 2011. p. 25-31.

MOISÉS, J.A. Cidade, povo e poder. Rio de Janeiro: Paz \& Terra, 1982.

MORAES, C.S.V. A socialização da força de trabalho: instrução popular e qualificação profissional no Estado de São Paulo (1873-1934). Bragança Paulista: Edusf, 2003.

MORAES, C.S.V. Educação permanente: direito de cidadania, responsabilidade do Estado. Trabalho, Educação e Saúde, Rio de Janeiro, v. 4, n. 2, p. 395-416, 2006.

MORAES, C.S.V.; ALAVARSE, O.M. Ensino médio: possibilidades de avaliação. Educação E Sociedade, Campinas, v. 32, n. 116, p. 807-838, jul./set. 2011.

MORAES, C.S.V.; CALSAVARA, T.; MARTINS, A.P. O ideário libertário e a relação trabalho e educação: algumas reflexões. Educação e Pesquisa, São Paulo, v. 38, n. 4, p. 997-1012, out./dez. 2012.

MORAES, C.S.V. et al. Inventário de fontes das escolas dirigidas pelo educador anarquista João Penteado (1912-1961). Revista Brasileira de História da Educação, Campinas, v. 11, n. 1 (25), p. 117-142, jan/abr. 2011.

OLIVEIRA, F. A economia brasileira: crítica à razão dualista. Estudos Cebrap, São Paulo, n. 2, out. 1972.

PEREIRA, L. Trabalho e desenvolvimento social no Brasil. São Paulo: Difel, 1965.

RODRIGUES, R.O.; SANTOS, M.I. Relações entre o público e o privado na educação profissional e tecnológica: alguns elementos para a análise do Pronatec. Revista de Educação, Ciência e Tecnologia, Canoas, v. 1, n. 2, 2012.

SIMONSEN, R. O trabalho moderno. São Paulo: Seção de Obras de "O Estado de S. Paulo", 1919.

SPOSITO, M.P. O povo vai à escola. São Paulo: Loyola, 1984. 
SPOSITO, M.P. A ilusão fecunda: a luta por educação nos movimentos populares. São Paulo: Hucitec, 2010.

TEIXEIRA, A. Educação no Brasil. São Paulo: Nacional, 1976.

Recebido em 24 de julho de 2013.

Aprovado em 20 de agosto de 2013. 